Diabetologia 7, 323-327 (1971)

(C) by Springer-Verlag 1971

\title{
Preventive Tolbutamide Treatment and Arterial Disease in Mild Hyperglycaemia*
}

\author{
J. PAasiktvi and F. Wahlberg \\ Department of Medicine, Karolinska Institutet at Serafimerlasarettet, Stockholm, Swedon
}

Received: May 26, 1971

Summary. In a study at the Serafimerlasarettet, Stockholm, it was found that low intravenous glucose tolerance (IVGT) in survivors from a first myocardial infarction without manifest diabotes refected a chronic state and implied a poor long term prognosis. In a controlled study of secondary prevontive treatment with tolbutamide in 178 such patients the survival rate improved significantly over $1 \frac{1}{2}-2$ yoars. This applied particularly to those with abnormal IVGT, who during the hospitalization had revealed signs suggestive of heart failure. - Also, the results of a controlled trial of primary preventive antidiabetic treatment performed in Bedford, England, showed that in 248 borderline hyperglycaemic individuals the incidence of new arterial events over $5-7$ years was significantly lower in those treated with tolbutamide. These findings indicate that progress of arterial disease assumed to be enhanced by impaired carbohydrate metabolism may be retarded by early tolbutamide treatment.

Traitment préventif par le tolbutamide et maladie artérielle dans l'hyperglycémie modérée

Résumé. Chez des patients hyperglycémiques, l'effet bénéfique d'une thérapeutique à long terme par le tolbutamide, constaté dans le présent travail ainsi que dans celui de Keen et collaborateurs, montre que la progression de la maladie artérielle, qui serait due à un métabolisme perturbé des hydrates de carbone, peut être retardée par un traitement au tolbutamide. - Il est possible cependant, en accord avec l'étude américaine de l'UGDP, qu'après une décompensation plus importante du métabolisme des hydrates de carbone aveo développement d'un diabète manifeste, le traitement par le tolbutamide ou l'insuline n'ait plus d'action bénéfique sur le système cardiovaseulaire, en comparaison avec le régime seul.
Präventivbehandlang mit Tolbutamid und arterielle Gefäßkrankheit bei milder Hyperglykämie

Zusammenfassung. In einer Untersuchung am Sera. fimerlasarettet, Stockholm, wurde festgestellt, daß eine niedrige intravenöse Glucosetoleranz bei Überlebenden eines ersten Myokardinfarktes ohne manifesten Diabetes einen chronischen Zustand widerspiegelt und eine schlechte Langzeit-Prognose bedeutet. In einer kontrollierten Studie der Sekundärprävention mit Tolbutamidbehandlung bei 178 solcher Patienten besserte sich die Überlebensrate signifikant über $1 \frac{1}{2}$ bis 2 Jahre. Dies traf besonders fiir Patienten mit abnormer intravenöser Glucosetoleranz zu, die während der Hospitalisierung Zeichen einer Herzinsuffizienz geboten hatten. - Die Ergebnisse eines kontrollierten Versuchs zur primärpräventiven, antidiabetischen Behandlung, der in Bedford, England durchgeführt worden war, zeigten ebenfalls, daß das Vor. kommen neuer arterieller Komplikationen bei 248 Personen mit Grenzfall-Hyperglykämien über 5 bis 7 Jahre bei denen signifikant niedriger war, die mit Tolbutamid behandelt worden waren. - Diese Befunde zeigen, daß die Progression der arteriellen Erkrankung, von der anzunehmen ist, daß sie durch den gestörten KohlonhydratStoffweehsel beschleunigt wird, durch frühzeitige Tol. butamidbehandlung verzögert werdon kann.

Key-words : Borderline hyperglycaemia, cardiovascular disease, controlled trial, heart failure, insulin, intravenous glucose tolerance, manifest diabetes, myocardial infare. tion, oral glucose tolerance, placebo, primary preventive treatment, secondary preventive treatment, serum cholesterol, serum triglycerides, tolbutamide.
The association between high levels of serum lipids and atherosclerotic disease has prompted a number of primary and secondary prevention trials over the last twen. ty years. Decreases in serum lipids have been achieved, but their effect on mortality is controversial [2].

Correspondingly, but more recently, it has been established that hyperglycaemia is linked to arterial disease, which has led to trials of antidiabetic treatment of subjects with milder degrees of chronic hyperglycaemia, i.e. without overt diabetes mellitus but with diabetic glucose tolerance. Some findings have suggested beneficial effects of such treatment $[5,6,10]$. On the other hand, recent results from an American study indicated an increased cardiovascular mortality with tolbutamide treatment in selected overt diabetics [12]. On account of these divergencies, an abbreviated presentation will be given of a trial that was per-

* This study was supported by grants from the Swed. ish National Acsociation against Heart and Chest Diseases. formed at Serafimerlasarettet, Stockholm, during the 1960s. A full report was published recently [10]. In a study from Serafimerlasarettet it was found that the intravenous glucose tolerance (IVGT) was abnormal in 66 per cent of 530 patients with intermittent claudication and angina pectoris or with a history of acute myocardial infarction but without manifest diabetes. This was four times the prevalence in 200 controls in whom it was abnormal in 14 per cent [13]. Similar figures have been obtained with oral glucose tolerance tests reported in the literature [13]. Epidemiological surveys in the USA, England and Australia have further confirmed these findings $[4,9,14]$. Wahlberg also found that abnormal IVGT 3-4 weeks after the acute myocardial infarction implied a poor long-term prognosis [13] (Fig. 1), and others have reported a similar prognostic implication of hyperglycaemia after myocardial infaretion [11] or in the presence of other arterial disease such as intermittent claudication [6]. 


\section{Material and Methods}

From January 1963 through July 1967, in all, 270 survivors from a first myocardial infaretion were discharged from the Serafimerlasarettet who fulfilled at least two of the following three diagnostic eriteria: a typical history, serum enzyme (SGOT, SGPT, LDH) pattern, and ECG findings suggestive of acute myocardial infarction. Ninety-two were excluded mainly because of history or signs of manifest diabetes or other disease known to interfere with carbohydrate metabolism, or refusal to participate. Thus there remained 178 patients, of whom 145 were men, mean age 58

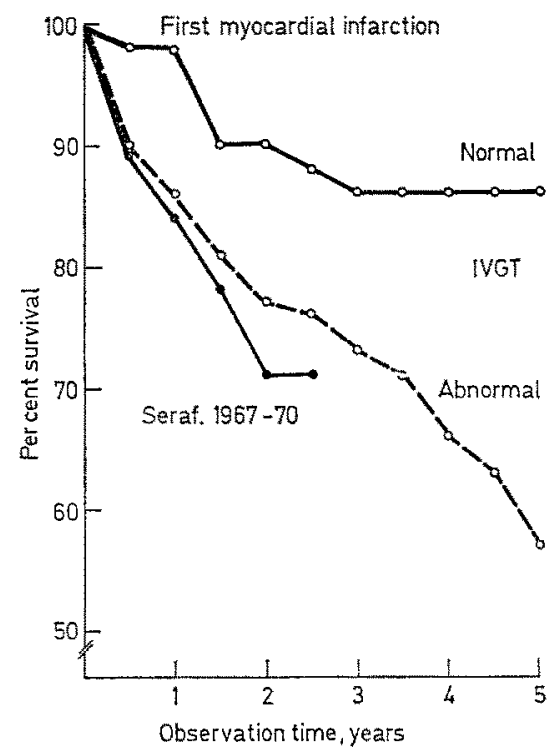

Fig. 1. Cumulative long-term survival after acute myocardial infaretion at Serafimerlasarettet $1960-65$ in relation to IVGT in 190 first infaretions and the corresponding total survival $1967-70$

years, and 33 women, mean age 68 years. At discharge from the hospital the patients were given tolbutamide or a placebo according to odd or even numbered birthdate. The 2 groups corresponded in all essential clinical respects. There were 95 patients in the tolbutamide-treatment group and 83 controls. The observation time ranged from $12-66$ months with an average of 3 years. Three patients withdrew from the study.

The initial prescription was half a tablet twice daily, with a routine stepwise monthly increase of the dosage to 2 tablets or $1 \mathrm{~g}$ tolbutamide daily in the absence of hypoglycaemic symptoms.

Before discharge from hospital and thereafter annually, the IVGT was tested with a single load of $25 \mathrm{~g}$ of glucose injected in 2-4 min. Using the formula $0.696 \times 100 / t_{1 / 2}\left(t_{1 / 2}-\right.$ half-life of the blood sugar $)$, the result of the test was expressed as a $k$-value representing the percentage disappearance rate of blood glucose per minute. $k$-values exeeeding 1.10 were classified as normal, others as abnormal. The test was performed after an overnight fast, and the research drug was discontinued 60 hours before the re-tests.

\section{Results}

In all 29 patients died during the follow-up. Sixteen $(19 \%)$ died in the control group which did not differ from $13(14 \%)$ in the tolbutamide group. All deaths were of probable cardiac origin. The mean age of those who died was 64 years irrespective of treatment. Their mean $\mathrm{k}$-values were also very similar $(0.95$ and 0.97$)$.

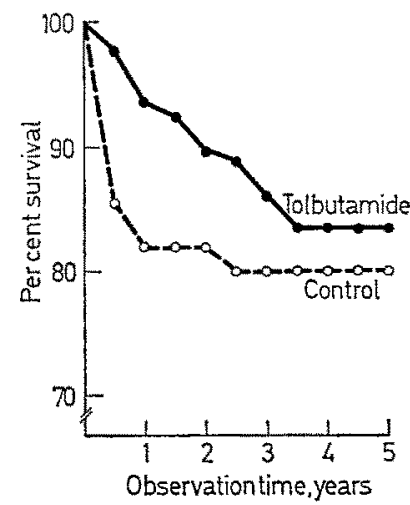

Fig. 2. Cumulative long-term survival in relation to tolbutamide treatment

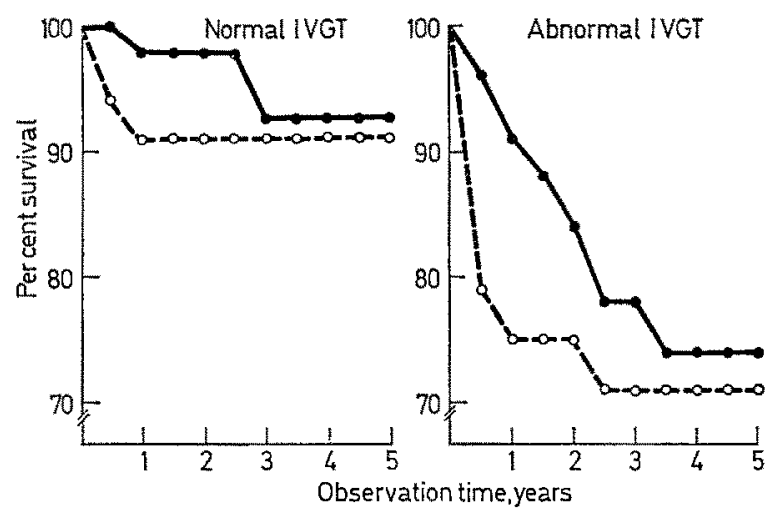

Fig. 3. Cumulativo survival in relation to IVGT lo - o control group

- tolbutamide group)

On the other hand, a significant difference in mortality was seen during the first 24 months. At this time, of those patients observed 2 years or more, 5/66 had died in the tolbutamide group as compared with 12/57 controls $(P<0.05)$. The eumulative survival is shown in fig. 2. The mean survival time of those who died in the 2 groups was 18 and 6 months, respectively $(P<0.05)$. Also nonfatal re-infarctions were postponed in the tolbutamide group, while no difference was observed as to other manifestations of arterial disease, such as angina pectoris or intermittent claudication. 
Fig. 3 shows the cumulative survival in relation to the IVGT determined 3-4 weeks after the acute myocardial infarction. The total mortality of the controls with abnormal IVGT (27\%) was significantly higher than in those with normal IVGT $(9 \%),(P<0.05)$. A significant effect of tolbutamide treatment occurred only in the patients with abnormal IVGT, the difference

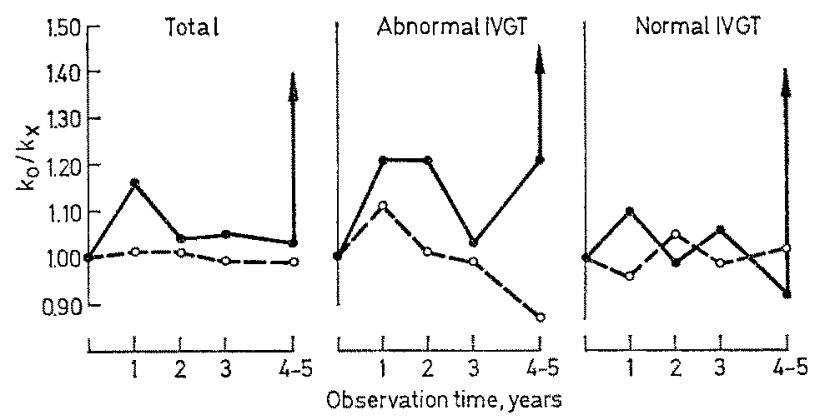

Fig. 4. The relationship of $k$-values obtained at repeated IVGT-tests $\left(k_{x}\right)$ to the initial $k$-value $\left(k_{0}\right)$ being normal or abnormal. The point of the arrow indicates the ratio of $k$-values of tests with and without prior interruption (o-o control group of tolbutamide treatment

in this subgroup being statistically significant over one year but not thereafter $(P<0.05)$.

Fig. 4 shows the IVGI at retests $\left(k_{x}\right)$ in relation to the initial IVGT $\left(k_{0}\right)$ of the retested subjects. Significant improvement was observed only in tolbutamidetreated patients with initially abnormal IVGT after one, 2 and $4-5$ years, while a stepwise decrease of IVGT occurred in corresponding controls being significant after $4-5$ years $(P<0.05)$. At retests without interruption of the tolbutamide treatment, which better corresponded to the actual situation of the treated patients, the difference was even greater, as indicated by the point of the arrow. Three controls developed manifest diabetes during the follow-up (initial $k$-values ranged $0.75-0.80$ ), but none of those treated with tolbutamine did.

In 46 randomly selected subjects serum cholesterol and triglycerides were determined before treatment and one year thereafter. No change in serum cholesterol was seen, the mean values being $249-255$ and $254-$ $256 \mathrm{mg} / 100 \mathrm{ml}$ in the control and tolbutamide groups, respectively. Significant changes of the serum triglycerides occurred only in those with initially abnormal IVGT, i.e. an increase from 1.99 to $2.88 \mathrm{mmol} /$ litre in controls, and a decrease from 2.41 to $1.88 \mathrm{mmol} /$ litre in tolbutamide-treated patients $(P<0.01)$, as illustrated by Fig. 5 .

$A$ number of clinical characteristics during the initial hospitalization were found to imply a poor prognosis, such as the occurrence of ventricular and supraventricular arrhythmias observed on routine ECGs. For the purpose of evaluation, patients with supraventricular ectopic beats (SVEB) and atrial fibrillation indicating pump failure, according to a suggestion by Lown and coworkers [8], were brought together with all those on digitalis therapy, to form a group of subjects who can be considered to represent those with heart failure during the hospitalization.

According to these criteria $50 \%$ of the total group of patients had been in failure. Of these, $31 \%$ died
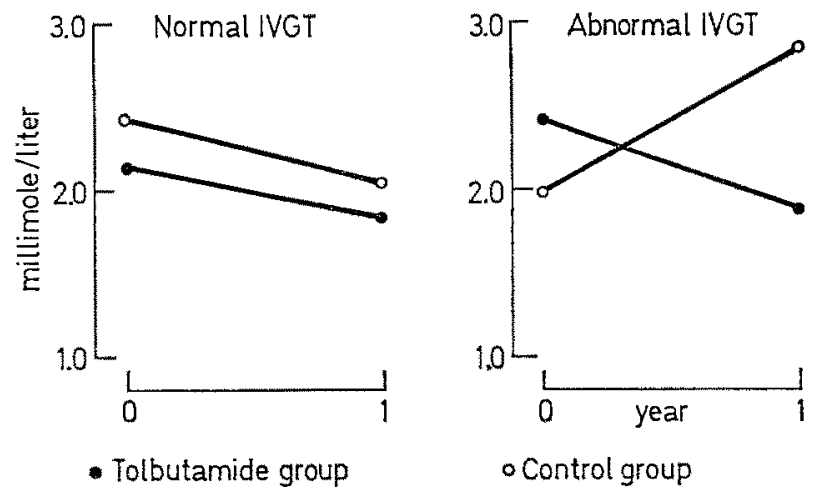

Fig. 5. Mean serum triglyceride levels in 46 patients at discharge from hospital and one year later

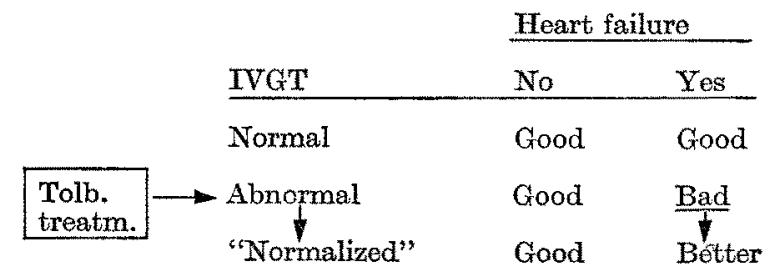

Fig. 6. Hypothetical relationship between IVGT, heart failure and tolbutamide treatment in relation to longterm survival after myocardial infarction

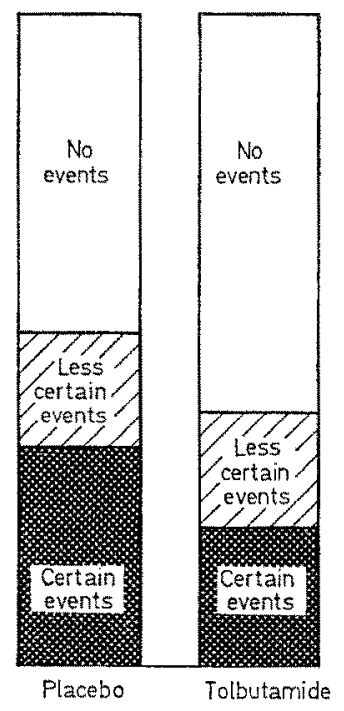

Fig. 7. The incidence of arterial events in borderline diabeties in relation to tolbutamide treatment over five years $^{5}$ 
during the follow-up compared with $3 \%$ of those who had not been in failure. Moreover, heart failure as defined here was also associated with abnormal IVGT, i.e. the incidence being $60 \%$ compared with $36 \%$ in those with normal IVGT $(P<0.05)$. Hence, the effect of treatment was mainly seen in these patients. Over one year, 27/31 in the tolbutamide group survived compared with $18 / 29$ controls $(P<0.05)$. This is also illustrated by Fig. 7 .

No serious side effects - vascular and non-vascular - were seen throughout the study.

\section{Discussion}

In the present study long-term tolbutamide treatment could be performed without serious side-effects, and was associated with improved survival over 2 years in survivors from a first myocardial infarction without manifest diabetes mellitus. This was observed particularly in those with abnormal IVGT, in whom it also improved glucose tolerance for $4-5$ years and decreased the serum triglycerides for at least one year after the acute episode. A high risk group comprising those with signs suggestive of heart failure seemed to benefit especially from the treatment.

The main part of the deaths in the control group occurred over the first 6 months upon discharge from hospital. Thereafter, the deaths in the tolbutamide group dominated until there was no statistical difference in overall mortality. This ought not to be explained as a harmful effect of tolbutamide. A more likely interpretation is that the beneficial influence of the drug was time-limited in a particular group of high risk, short-term survivors from a myocardial infarction. The great resemblance of the deceased in the 2 treatment groups is illustrated by their mean ages and mean $k$-values being almost identical.

An improvement of glucose tolerance by tolbutamide treatment in subjects without manifest diabetes was first observed by Fajans and Conn [3], but later reports have been at variance in this respect [10]. Even during continuous tolbutamide therapy the blood. sugar-lowering influence may be small, although significant $[5,6]$. In the present study, a definite improvement of IVGT was found still after $4-5$ years treatment.

Eight out of the 13 who subsequently died in the tolbutamide group were retested at least once after discharge from hospital. No different tendency in their IVGT in comparison with the long-term survivors could be traced. Apparently an improvement of the glucose tolerance only cannot explain the beneficial effect of tolbutamide regarding the survival.

The importance of the lowering of the serum triglycerides observed in a subgroup is unfortunately difficult to assess, since information about the serum lipids is lacking in the majority of the patients. On the other hand, no secondary prevention trial has so far shown a decrease of serum triglycerides to be associated with a. significant improvement in mortality [2].

Berchtold et al. have also found a diminished glucose tolerance 3 months after myocardial infarction [1]. The impairment was more pronounced in those who had had large myocardial damage or complications of the acute myocardial infarction. This seems to be in accordance with the present finding of abnormal IVGT in those with signs indicating heart failure. Another sign of failure is cardiac enlargement. In the present study, the mean relative heart volume at discharge from hospital was significantly greater $\left(508 \mathrm{ml} / \mathrm{m}^{2}\right.$ BSA) in this latter group compared with that without signs of heart failure $\left(435 \mathrm{ml} / \mathrm{m}^{2} \mathrm{BSA}\right.$ ). Furthermore, the findings in 70 survivors of one or more myocardial infarctions treated at the coronary care unit at Serafimerlasarettet seem to support this association. The relation of IVGT to the clinical diagnosis of heart failure used at this unit is shown in Table 1 . It is seen that $9 / 25(36 \%)$ of the patients with normal IVGT had been in failure compared with $29 / 45$ $(64 \%)$ with abnormal IVGT $(P<0.05)$.

Table 1. IVGT after myocardial infarction and heart failure during the acute episode

\begin{tabular}{|c|c|c|c|c|}
\hline \multirow[b]{2}{*}{ IVGT } & \multirow[b]{2}{*}{ Mean age } & \multirow[b]{2}{*}{ No. } & \multicolumn{2}{|c|}{ Heart failure } \\
\hline & & & No. & Per cent \\
\hline Total & 63.6 & 70 & 38 & 54 \\
\hline Normal & 62.5 & 25 & 9 & 36 \\
\hline Abnormal & 64.2 & 45 & 29 & 64 \\
\hline
\end{tabular}

The improved survival in the tolbutamide group seems to be in accordance with the findings of a doublem blind controlled therapeutic trial on 248 "borderline hyperglycaemic" individuals in Bedford, England. The participants were randomly assigned to tolbutamide treatment $(0.5 \mathrm{~g}$ twice daily) or placebo treatment. They were re-examined regularly every sixth month. Over the first 5 years, the incidence of new arterial events was significantly lower in the tolbutamide group compared with those who received placebo [5] (Fig. 7). Over 7 years a significant difference was still seen in those who at entry had no signs of cardiovascular disease or clinically significant hypertension [6].

On the other hand, a controlled American study, The University Group Diabetes Program (UGDP), suggests an adverse effect of tolbutamide in patients with manifest diabetes mellitus [12]. In a multicentre, elaborate trial, 823 patients with symptomatic maturity-onset diabetes with a duration of less than one year were followed over 8 years. They were randomly treated with diet and either $1.5 \mathrm{~g}$ tolbutamide daily, standard insulin in a fixed or a variable dosage, or a placebo. It was found that the incidence of cardiovascular death was significantly higher in the tolbutamide group than in the placebo group (26/204 and 10/205, respectively). This surprising result being at variance with clinical experience led. 
to much criticism from a number of diabetologists, especially after a statement had been given by the Food and Drug Administration (Nov. 2, 1970) restricting the use of sulphonylurea drugs in the USA. The critics have claimed that the tolbutamide-treated subjects carried more risk factors at entry than did the other participants, particularly those receiving a placebo. The significance of this difference has been disputed by the American investigators [15]. A crucial point is perhaps also the low and differing autopsy rates in the cases classified as cardiovascular death: $13 / 26$ in the tolbutamide, $2 / 10$ in the placebo, and $5 / 25$ in the insulin-treated groups.

The incidence of non-fatal cardiovascular events such as significant ECG abnormalities, hypertension and arterial calcification was unaffected by the treatment in the UGDP study.

Summarizing, the beneficial effect of long-term treatment with tolbutamide in hyperglycaemic subjects in the present study and in that of Keen and others, indicates that a progress of arterial disease assumed to be enhanced by impaired carbohydrate metabolism may be retarded by tolbutamide treatment $[5,6]$.

It may be, however, according to the American UGDP, that after a further decompensation of the carbohydrate metabolism with development of overt diabetes, there are no cardiovascular benefits to be achieved by tolbutamide or insulin treatment compared with diet only.

\section{References}

1. Berchtold, P., Björntorp, P., Lindholm, B., Tibblin, G., Wilhelmsen, L.: Glucose tolerance, plasma insulin and lipids in men after myocardial infarction. Diabetes, in press (1971).

2. Dayton, S.: Diet and ischemic heart disease. Progress in secondary prevention dietary trials. In: Jones, R.J. (Ed.) : Atherosclerosis: Proceedings of the second international symposium. Springer-Verlag, Berlin, Heidelberg, New York, p. 577-582 (1970).

3. Fajans, S.S., Conn, J.W.: Tolbutamide-induced improvement in carbohydrate tolerance of young people with mild diabetes mellitus. Diabetes 9, $83-88$ (1960).
4. Keen, H., Rose, G., Pyke, D.A., Boyns, D., Chlouverakis, C., Mistry, S.: Blood sugar and arterial disease. Lancet 1965 II, 505-508.

5. - Jarrett, R.J., Chlouverakis, C., Boyns, D.R.: The effect of treatment of moderate hyperglycemia on the incidence of arterial disease. Postgrad. med. J. Suppl. 960-965, Dec. (1968).

6. - - The effect of carbohydrate tolerance on plasma lipids and atherosclerosis in man. In: Jones, R.J. (Ed.): Atherosclerosis: Proceedings of the second international symposium. Springer-Verlag, Berlin, Heidelberg, New York, p. 435-444 (1970).

7. Kingsbury, K.J.: The relation between glucose tolerance and atherosolerotic vascular disease. Lancet 1966 II, $1374-1379$.

8. Lown, B., Klein, M.D., Hershberg, P.I.: Coronary and precoronary care. Amer. J. Med. 46, 705-724 (1969).

9. Ostrander L.D.: Hyperglycemia and vascular disease in Tecumseh, Michigan. In: Camerini-Dávalos, R.A.\& Cole, H.S. (Ed.): Early diabetes, Academic Press, New York and London, p. 365-370 (1970).

10. Paasikivi, J. : Long-term tolbutamide treatment after myocardial infarction. A clinical and biochemical study of 178 patients without overt diabetes. Acta med. scand. Suppl. 507, $1-82(1970)$.

11. The Coronary Drug Project Research Group: Control of hyperlipidemia. In : Jones, R.J. (Ed.) : Atherosclerosis : Proceedings of the second international symposium. Springer-Verlag, Berlin, Heidelberg, New York, p. $586-595(1970)$.

12. The University Group Diabetes Program. A study of the effects of hypoglycemic agents on vascular complications in patients with adult-onset diabetes. Diabetes 19, Suppl. 2, 747-830 (1970).

13. Wahlberg, F.: Intravenous glucose tolerance in myocardial infarction, angina pectoris and intermittent claudication. Acta med. scand. Suppl. 453, 1-93 (1966).

14. Welborn, T.A., Cumpston, G.N., Cullen, K.J., Curnow, D.H., McCall, M.G., Stenhouse, N.S.: The prevalence of coronary heart disease and associated factors in an Australian rural community. Amer. J. Epidemiol. 89, 521-536 (1969).

15. Indications and side-effects of oral antidiabetic therapy. Meeting arranged by Deutsche DiabetesGesellschaft, Düsseldorf, February 12-13 (1971).

Juhani Paasikivi, M.D.

Birger Jarlsg. 36

S-114 29 Stockholm, Sweden 